\title{
Multifunctional UV and Gas Sensors Based on Vertically Nanostructured Zinc Oxide: Volume Versus Surface Effect
}

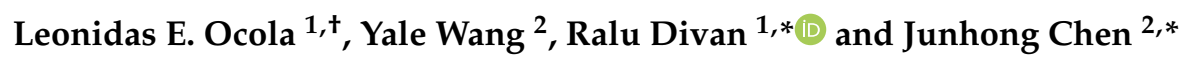 \\ 1 Argonne National Laboratory, 9700 S-Cass Avenue, Argonne, IL 60439, USA; ocola1962@gmail.com \\ 2 Department of Mechanical Engineering, University of Wisconsin-Milwaukee, 3200 N Cramer Street, \\ Milwaukee, WI 53211, USA; yalewang@uwm.edu \\ * Correspondence: divan@anl.gov (R.D.); jhchen@uwm.edu (J.C.) \\ † Present address: IBM T. J. Watson Research Center, Yorktown Heights, NY 10598, USA
}

Received: 8 March 2019; Accepted: 24 April 2019; Published: 2 May 2019

\begin{abstract}
This article reports that it is possible to make multifunctional sensing devices with $\mathrm{ZnO}$ infiltrated polymers while the sensing interactions could occur throughout the polymer. As such, we find that infiltrated devices with SU-8 polymer can result in highly sensitive UV sensors. Mesh dielectric core devices were found to make sensitive gas sensors with a better than $5 \mathrm{ppm}$ sensitivity for formaldehyde and $\mathrm{NO}_{2}$. A new type of $\mathrm{p}$ - $\mathrm{n}$ junction device is further demonstrated that is sensitive to UV illumination, thus making it an enhanced UV sensor. Sensing devices relying on volume interactions, such as light absorption, can significantly benefit from the infiltrated polymer. In contrast, devices that rely on surface interactions, such as gas sensors, do not gain performance in any significant way with or without the infiltrated polymer.
\end{abstract}

Keywords: gas sensor; polymer infiltration; UV sensor; atomic layer deposition

\section{Introduction}

Metal oxides have been widely investigated and applied in chemoresistive gas sensors [1], photocatalysis [2,3] (Liu et al., 2013; Liu et al., 2014), optoelectronic devices [4,5], and water treatment [6,7]. Zinc oxide $(\mathrm{ZnO})$ applied in these applications takes the form of nanoparticles, nanorods, or thin films. These crystalline or polycrystalline metal oxides are grown via chemical synthesis or physical deposition and have been extensively characterized [8,9]. In this paper, a different growth method of $\mathrm{ZnO}$ inside a polymer film is studied. The large bandgap and semiconductor properties of $\mathrm{ZnO}$ allow for a visible-blind ultraviolet light sensor.

$\mathrm{ZnO}$ nanoparticles or quantum dots have been incorporated inside polymers for many years. Their optical properties have been combined to develop new applications, like nonlinear optics [10], photovoltaic applications [11,12], and UV-Vis absorbers [13]. ZnO could be combined with a transparent matrix to form suitable UV-shielding materials, filters, and luminescent films. With the increased portfolio of materials that can be deposited using atomic layer deposition (ALD), there has been an increased interest in infiltrated metal oxides [14], such as zinc oxide, in terms of the fundamental understanding of growth properties in resistive polymers, such as poly (methyl methacrylate) (PMMA) [15] and the negative resist SU-8 [16]. The concepts of the infiltration method are similar to the ALD process. ALD is a vapor phase deposition technique with precise thickness control and high uniformity [17]. The infiltration method is a variant of ALD specifically to coat inside walls of porous materials, but the process exposure time, pressure, and purpose are significantly different. The purpose is to allow the precursor gases to infiltrate the polymer matrix (e.g., SU-8) and the reaction to occur inside the polymer matrix. 
Introduction of infiltrated $\mathrm{ZnO}$ in SU-8 for novel device fabrication has also been addressed in prior work $[18,19]$. SU- 8 is a negative resist that can be exposed with UV light at $385 \mathrm{~nm}$ and also with high energy electron beams. In the work by Nam et al., the SU-8 polymer was removed via oxygen plasma etch after infiltration and left behind pure $\mathrm{ZnO}$ nanowires $[18,19]$. This report discusses the effect of leaving the infiltrated polymer as part of the fabrication of transparent UV and gas sensor devices. The advantages of infiltration over simple ALD coating as part of the fabrication process has been investigated.

\section{Experimental}

\subsection{Energy-Dispersive X-Ray Spectroscopy (EDS) Characterization}

The penetration depth of the infiltration process in SU-8 was determined by infiltrating an SU-8 film that was first flood-exposed to create a uniform $1 \mu \mathrm{m}$-thick thin film that would allow energy-dispersive $X$-ray spectroscopy (EDS) cross section characterization. The sample was infiltrated with 12 cycles of water and diethylzinc $\left[\mathrm{H}_{2} \mathrm{O}: \mathrm{DEZ}\right]$, then cleaved and tilted to expose the lateral side to an electron beam in a field emission scanning electron microscope JEOL 7500 FESEM. Each half cycle of $\mathrm{H}_{2} \mathrm{O}$ and DEZ lasted 4 min and processed at $95^{\circ} \mathrm{C}$. Figure 1 shows the EDS data of the L-shell for $\mathrm{Zn}$ and the K-shell for the $\mathrm{Al}_{2} \mathrm{O}_{3}$ seed layer used to enhance $\mathrm{ZnO}$ formation inside the polymer [11]. The data shows that the penetration depth can reach about $500 \mathrm{~nm}$ into the resist. This means that if the fabricated SU-8 structures are on the order of $1 \mu \mathrm{m}$ in width, then it is reasonable to expect that the entire structure will be saturated with infiltrated $\mathrm{ZnO}$. Another detail can be assessed from Figure 1, in which there is no evidence of $\mathrm{ZnO}$ nanoparticle formation, where polymer nanoparticle interfaces can be seen. It is thus reasonable to expect a uniform distribution of $\mathrm{ZnO}$ in the infiltrated region. A comprehensive investigation on the growth of zinc oxide in a polymer matrix using photoluminescence (PL), Raman, and X-ray photoemission spectroscopy (XPS) has been reported in our previous paper [15].

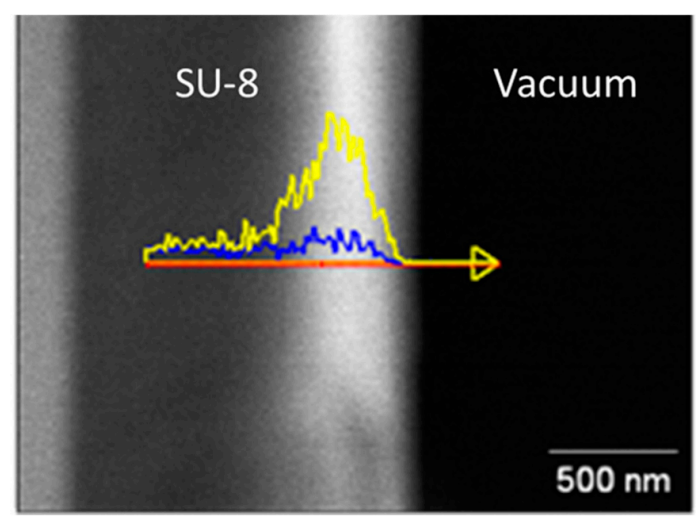

Figure 1. Energy-dispersive X-ray spectroscopy (EDS) data of the L-shell for Zn (yellow) from infiltrated $\mathrm{ZnO}$ and the K-shell for $\mathrm{Al}$ (blue) from the $\mathrm{Al}_{2} \mathrm{O}_{3}$ seed layer in SU-8 (cross sectional view).

\subsection{Sensor Fabrication}

The device under test is a novel design with an enhanced surface area for both light absorption and gas sensing [20]. It is based on locating the sensing material over a set of interdigitated electrodes that cover a $20 \mu \mathrm{m} \times 200 \mu \mathrm{m}$ area with electrode fingers $300 \mathrm{~nm}$ wide and placed at a $1 \mu \mathrm{m}$ pitch. The use of interdigitated electrodes covered with the sensing metal oxide material has been shown to render high sensitivity and good performance [21].

A schematic of the device to be discussed is illustrated in Figure 2. We locate a dielectric core surrounded by infiltrated polymer that connects two electrodes. The dielectric core forces the electric current between electrodes out of the plane and into the sensing media. It is made by patterning $1 \mu \mathrm{m}$-thick hydrogen silsesquioxane (HSQ) resist with $100 \mathrm{KV}$ electrons at a dose of $7000 \mu \mathrm{C} \cdot \mathrm{cm}^{-2}$, 
and developed in a 1:3 diluted solution of Microposit 351 developer in water for 5 min. After the fabrication of the dielectric core, $1.5 \mu \mathrm{m}$ of SU- 8 was spin coated, baked at $100{ }^{\circ} \mathrm{C}$ for $3 \mathrm{~min}$, exposed at a dose of $28 \mu \mathrm{C} \cdot \mathrm{cm}^{-2}$ at $100 \mathrm{KV}$, and developed in an SU-8 developer for $2.25 \mathrm{~min}$. The SEM layout images of the device are indicated in Figure S1 in Supporting Information.

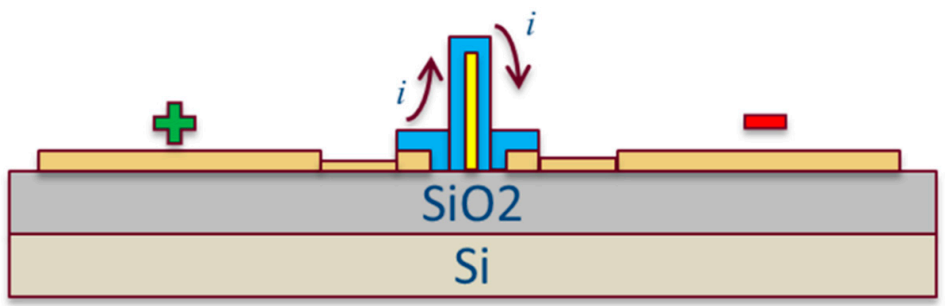

Figure 2. Schematic of the device structure of the UV and gas sensor. A vertical dielectric core (HSQ) is surrounded by infiltrated polymer (SU-8) that connects two electrodes ( + and - ), forcing the current $(i)$ to go up and over the dielectric core.

\section{Results and Discussions}

A first device was fabricated with 12 cycles of infiltrated $\mathrm{ZnO}$ as shown in Figure 3a,b. The sample was cured at $400{ }^{\circ} \mathrm{C}$ to improve the $\mathrm{ZnO}$ crystallization and thus improve the current.

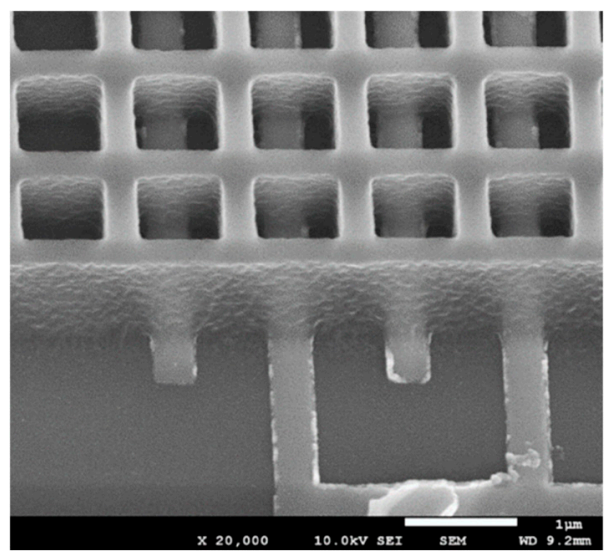

(a)

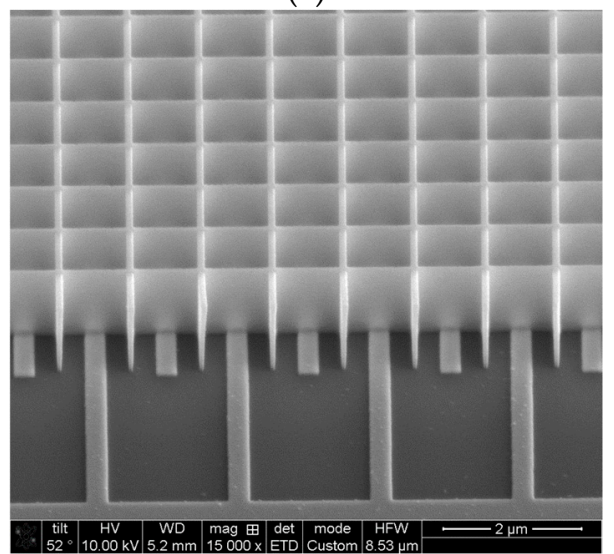

(c)

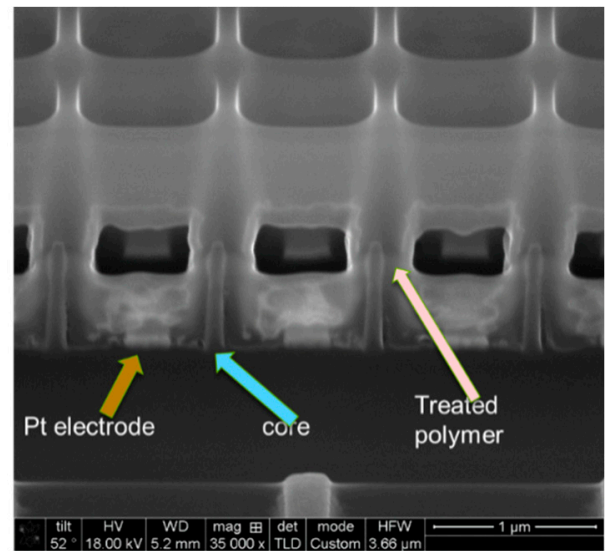

(b)

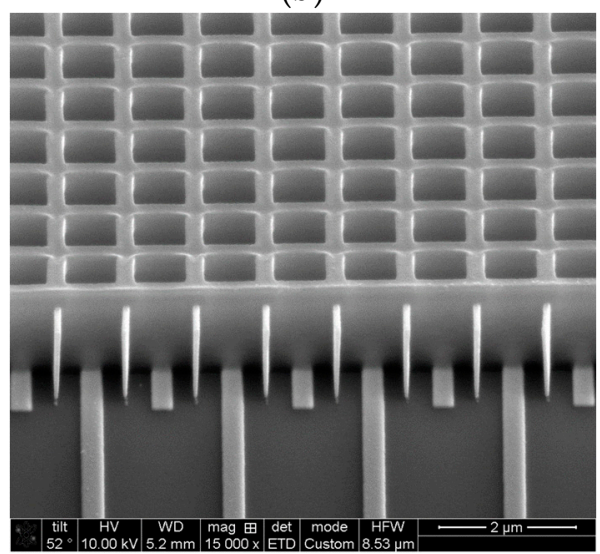

(d)

Figure 3. SEM micrographs showing key aspects of a fabricated device after infiltration. (a) Image shows a $1 \mu \mathrm{m}$ tall-300 $\mathrm{nm}$ wide mesh structure over a set of interdigitated electrodes. (b) Image of the same device after focused ion beam (FIB) cross sectioning exposing the dielectric core, Pt electrodes, and infiltrated SU-8 polymer. (c,d) Devices fabricated with extra dielectric core fins to ensure electrical current goes over the core into the sensing media (c) device with only a core and no polymer, and (d) device with core and polymer. 
A second generation of devices with an improved design to ensure that all current between electrodes does indeed enter the sensing media were fabricated and are shown in Figure $3 c$,d. In addition, these devices were used to determine if adding the polymer for infiltration improved the performance of the device or not. Therefore, both devices received the exact same infiltration treatment, thermal annealing (in this case, at $300{ }^{\circ} \mathrm{C}$ in an oxygen-rich atmosphere). The lower temperature was used to minimize any chance of polymer degradation during annealing. In this case, it could be drawn at low voltages to maximize the current, the samples were subjected to 36 cycles of infiltrated $\mathrm{ZnO}$, plus a coating of a $\mathrm{ZnO}$ and a $\mathrm{TiO}_{2}$ bilayer of 36 cycles each. $\mathrm{TiO}_{2}$ was used for a dual purpose. First, $\mathrm{TiO}_{2}$ helps stabilize $\mathrm{ZnO}$ [2], and second, the heterostructure formed between $\mathrm{ZnO}$ and $\mathrm{TiO}_{2}$ facilitates charge separation [22]. In order to ensure there was no difference in the processing of these devices, they were both fabricated on the same silicon substrate and infiltrated in the same chamber while on the same wafer substrate. Therefore, any performance difference was only due to the presence or not of the polymer.

Given that infiltration is an ALD-based technique, it is expected that the $\mathrm{ZnO}$ will coat the entire wafer. Therefore, before any sensing experiments, the $\mathrm{ZnO}$ was etched back from all areas with the exception of the sensing region in the mesh region. This prevents shorts between the electrodes and forces the electrical current through the out-of-plane mesh structures, thus enhancing the interaction of the electrical current in the metal oxide with the surrounding media.

\subsection{Response to UV Light}

$\mathrm{ZnO}$ has been widely investigated as visible and ultraviolet (UV) light photodetection materials for decades. The first structure of the infiltration $\mathrm{ZnO}$ in a polymer matrix with the vertical dielectric core increased the sensing surface area compared with the thick $\mathrm{ZnO}$ film. The initial results using this first device as a UV sensor are shown in Figure 4. The current as a function of the driving voltage with a UV Light-Emitting diode (LED) turned off and on was measured. The spectral range of the UV LED is shown in Figure $4 a$, while the I-V curve is shown in Figure $4 b$. The device was able to achieve a current of $650 \mathrm{nA}$ at $2 \mathrm{~V}$ under $408 \mathrm{~nm}$ UV light illumination.

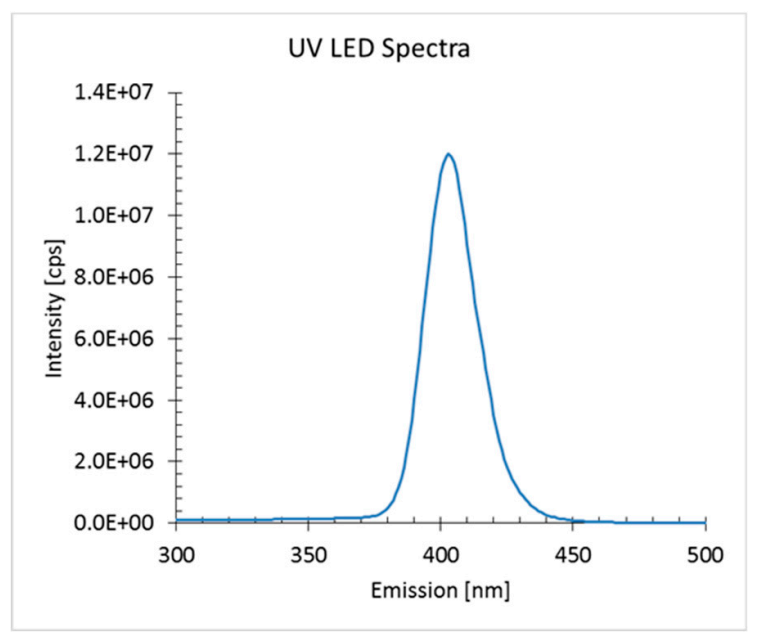

(a)

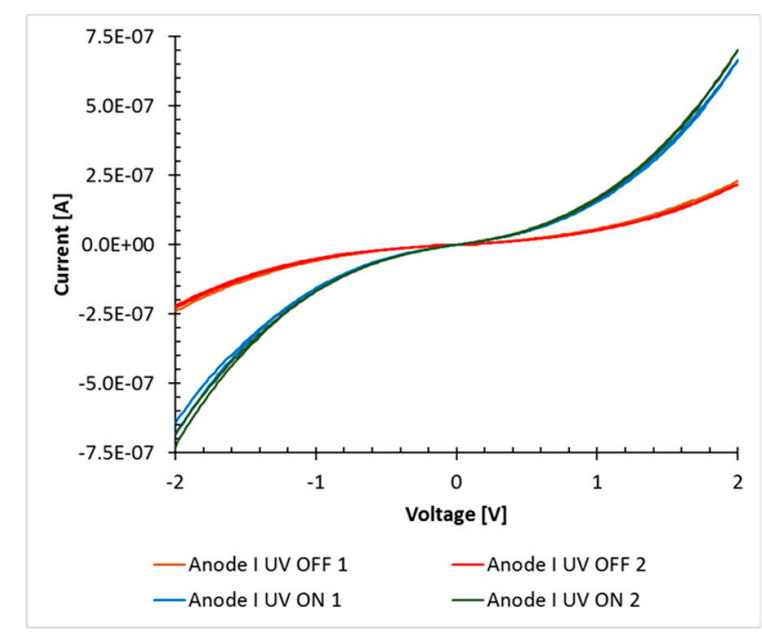

(b)

Figure 4. First UV sensing results with infiltrated ZnO. (a) Spectral range of the UV LED used. (b) Current vs. voltage (I-V) curve with the UV Light-Emitting Diode (LED) turned off and on (dark line going from $-650 \mathrm{nA}$ to $+650 \mathrm{nA}$ at $\pm 2 \mathrm{~V})$.

The comparison of the UV sensing performance between devices is shown in Figure 5a. The data is the current measured at $5 \mathrm{~V}$ after cycling the electrode voltage from $-5 \mathrm{~V}$ to $+5 \mathrm{~V}$ with the UV LED source at $408 \mathrm{~nm}$ off and on. The time for a voltage sweep took about $30 \mathrm{~s}$. Figure $5 \mathrm{~b}$ demonstrates the current change of the SU8 and the HSQ devices as a function of time. As can be seen on the plot, 
the device with the polymer has a stronger change in the current than the device made with only the dielectric core. This can be explained as the UV light is absorbed by the full device, including the coating polymer and infiltrated $\mathrm{ZnO}$. A second test using a $365 \mathrm{~nm}$ UV source generated by a UV-AC lamp purchased from VWR, which is more energetic, shows that the infiltrated devices with polymer have a sub 10 s response 200 to 300 times (20,000\% to 30,000\%) change in current, Figure $5 c, d$. The UV photoresponse current was monitored by a Keithley 2602 source meter at $2 \mathrm{~V}$ bias. The current at $2 \mathrm{~V}$ was of the order of tens of nA with the $365 \mathrm{~nm}$ UV light off. Then, it jumped to the order of tens of $\mu \mathrm{A}$ with the UV light on. Data are normalized to the average current measured before the UV light was turned on. The three data sets in Figure 5 correspond to the different fabrication recipes.

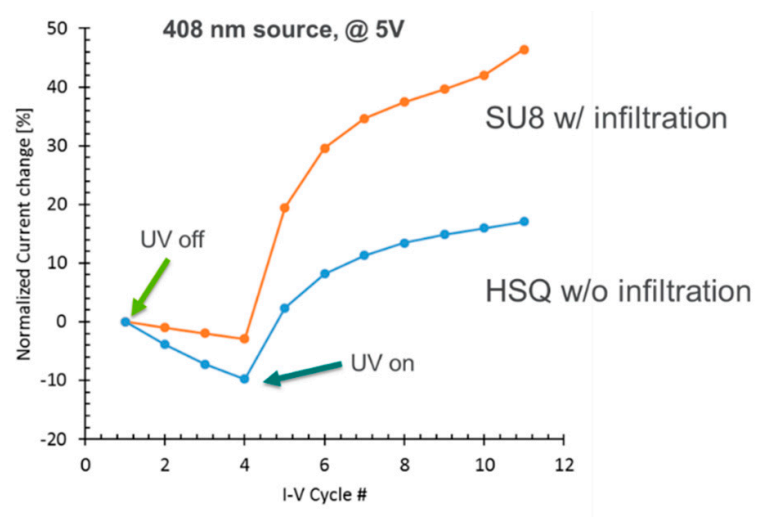

(a)

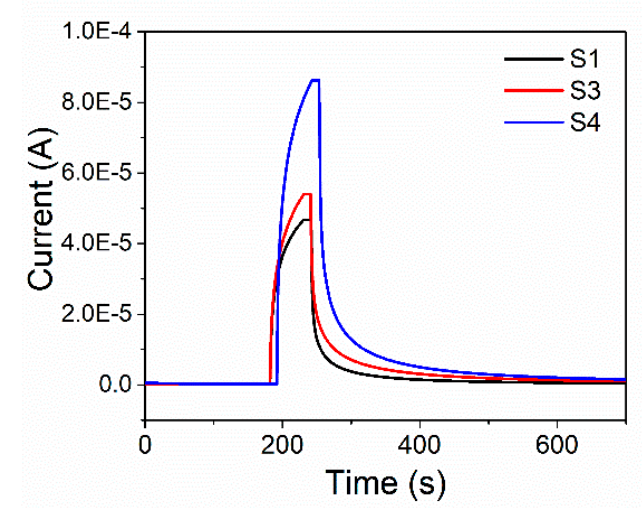

(c)

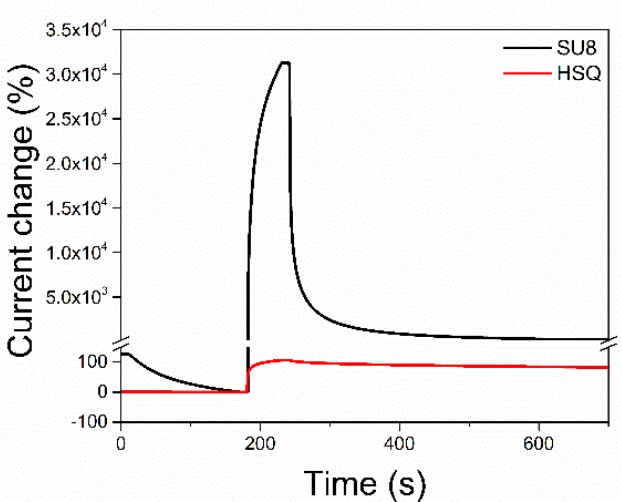

(b)

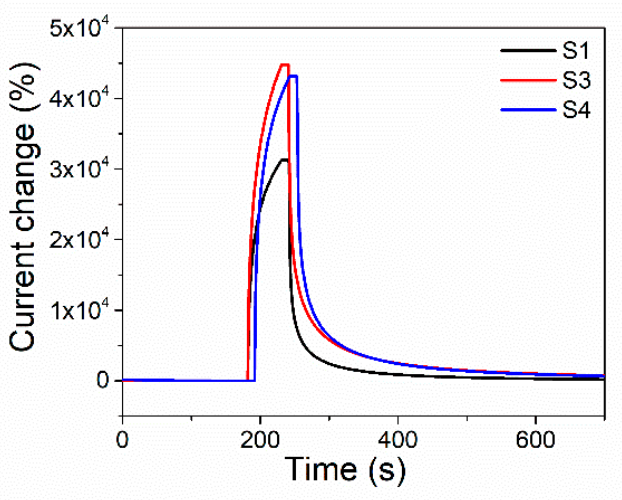

(d)

Figure 5. (a) Change of current at $5 \mathrm{~V}$ when turning on UV LED at $408 \mathrm{~nm}$ in $30 \mathrm{~s}$ intervals for devices with the hydrogen silsesquioxane (HSQ) dielectric core with/without w/o infiltration, and with photoresist polymer (SU-8) with infiltration. (b) Change of current vs. time when turning on UV lights for devices with a HSQ dielectric core, and with SU-8 polymer. (c,d) Change of current vs. time for infiltrated devices with SU-8 polymer taken at $2 \mathrm{~V}$. S1 recipe: $\mathrm{H}_{2} \mathrm{O}, \mathrm{BA}-\mathrm{MeOH}, \mathrm{H}_{2} \mathrm{O}$; $\mathrm{S} 3$ recipe: $\left(\right.$ DEZ, $\left.\mathrm{H}_{2} \mathrm{O}\right) \times 2$ cycles, $\mathrm{BA}-\mathrm{MeOH}, \mathrm{H}_{2} \mathrm{O}$; 4 recipe: $\left(\right.$ DEZ, $\left.\mathrm{H}_{2} \mathrm{O}\right) \times 2$ cycles, $\left(\mathrm{BA}-\mathrm{MeOH}, \mathrm{H}_{2} \mathrm{O}\right) \times 2$ cycles. (c) Current vs. time showing actual current in Amps. (d) Percentage change of current vs. time normalized to the average current before turning on the UV light source.

Figure $5 \mathrm{~d}$ indicates the UV sensitivity $\left(\frac{I_{U}-I_{a}}{I_{a}}\right)$ of the $\mathrm{S} 3$ sensor reached $4.5 \times 10^{4}$, which is comparable with the highest ratio $\left(1 \times 10^{4}\right.$ to $\left.1 \times 10^{5}\right)$ reported in the literature [23,24]. $I_{U}$ represents the current with the UV light turned on and $I_{a}$ represents the current with the UV light turned off. We also investigated the stability performance of the UV sensor in Figure S2.

To create a p-n junction with the coated and infiltrated $\mathrm{ZnO}$, one of the interdigitated platinum electrodes was replaced by a boron-doped patterned amorphous silicon electrode, and images of the devices used are shown in Figure 6a,b. Preliminary results clearly show rectification by the devices 
with and without UV light exposure, Figure $6 c, d$. It is apparent that the p-n junctions with $\mathrm{ZnO}$ infiltrated SU-8 polymer are more conductive than its counterparts. It is believed that this is due to the conduction below the polymer surface, which contributes to the total conductivity. The kink in the high current region is believed to be an artifact from the acquisition hardware.

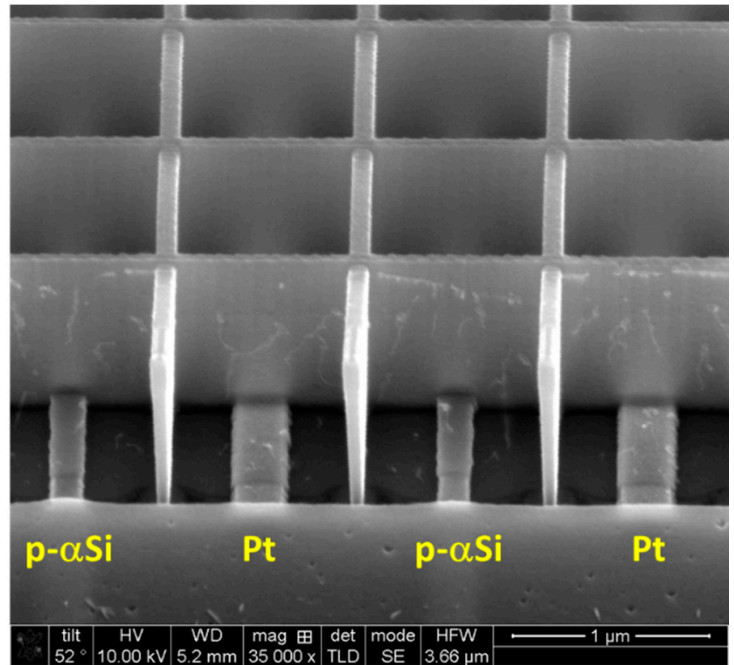

(a)

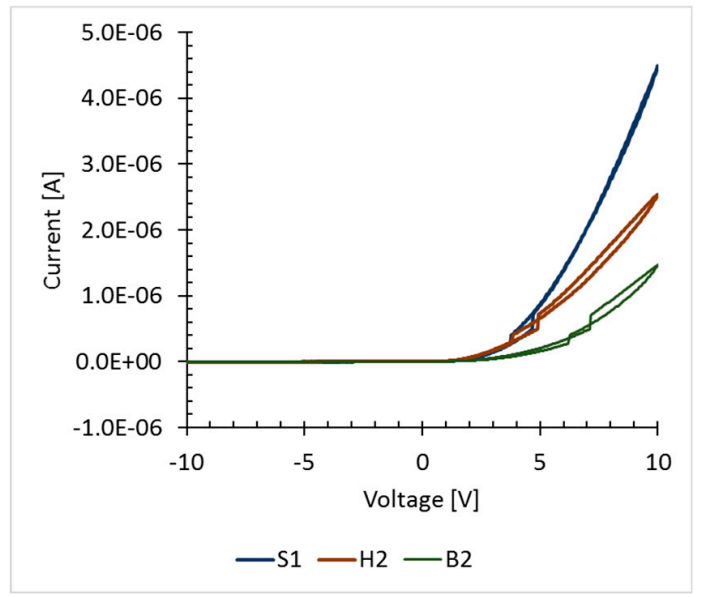

(c)

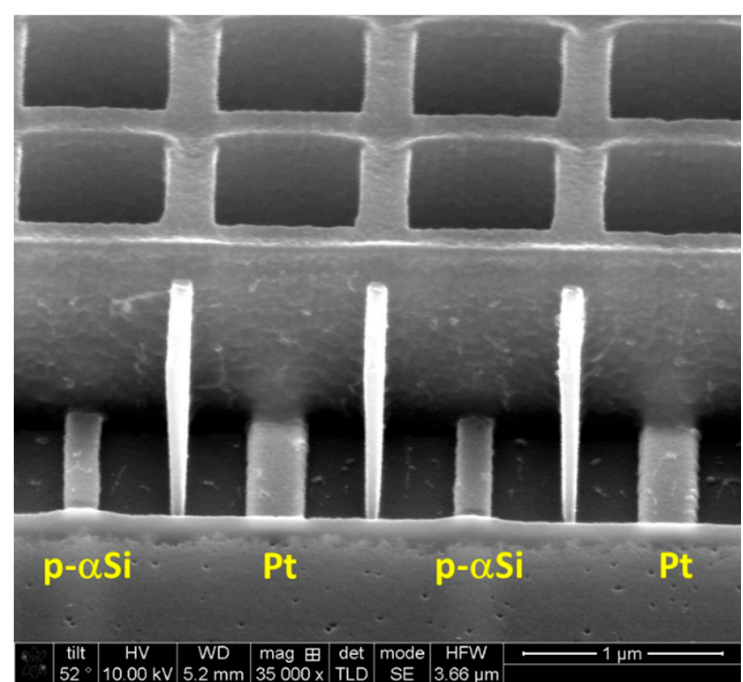

(b)

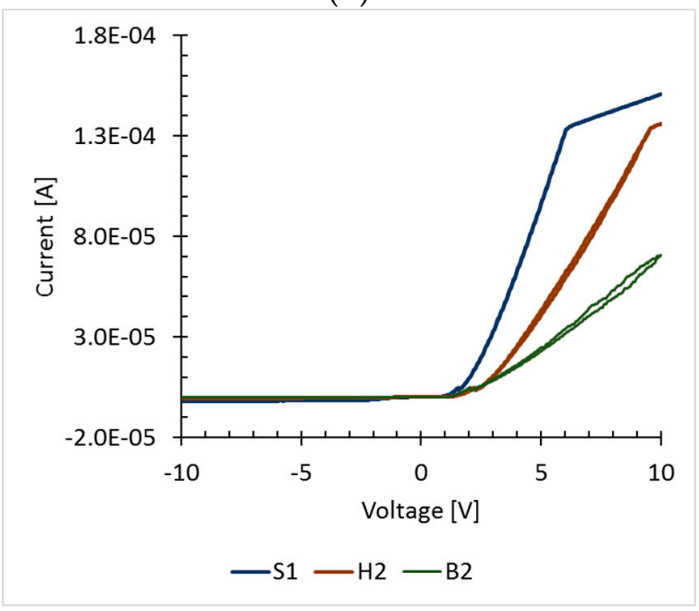

(d)

Figure 6. SEM images of the p-n junction devices with coated or infiltrated ZnO. (a) Device with dielectric core coated with $\mathrm{ZnO}$. (b) Device with $\mathrm{ZnO}$ infiltrated SU-8 polymer. Current vs. voltage plots of p-n junctions with coated or infiltrated $\mathrm{ZnO}$. Device S1 corresponds to a device with $\mathrm{ZnO}$ infiltrated SU-8 polymer. Device H2 corresponds to a ZnO coated dielectric core device. Device B2 corresponds to a non-patterned device where $\mathrm{ZnO}$ is coating the electrodes directly with no dielectric core mesh. Note the difference in scales between UV off data (c) and UV on data (d) is almost two orders of magnitude.

\subsection{Response to Formaldehyde and $\mathrm{NO}_{2}$}

The gas sensing properties with the same devices were investigated. The gas sensing test system consists of a home-made chamber, a Keithley 2602 source meter for current monitoring and source-drain voltage application, and two mass flow controllers connected to air and testing gas cylinders. The first generation of devices was tested for formaldehyde and $\mathrm{NO}_{2}$. As a background, the recommended formaldehyde gas exposure limits are: STEL: 0.3 (ppm) from ACGIH (TLV) (United States), STEL: 2 (ppm) from OSHA (PEL) (United States), STEL: 2 (ppm) (United Kingdom (UK)) [25]. The exposure limits for $\mathrm{NO}_{2}$ are 5 ppm OSHA ceiling, 1 ppm OSHA STEL, 3 ppm ACGIH TWA, 5 
ppm ACGIH STEL, and 1 ppm NIOSH recommended STEL [26]. STEL is short-term exposure limit, TLV is threshold limit value.

These chemiresistive gas sensors responded to analyte gases with a current change due to the carrier density modification effect from the gas molecule interaction with the sensing material surface. The sensitivity is defined as $\mathrm{S}=\frac{\left(I_{g}-I_{a}\right)}{I_{a}}$, where $\mathrm{I}_{\mathrm{g}}$ represents the current in gas and $\mathrm{I}_{\mathrm{a}}$ represents the current in air. The first test and Figure $\mathrm{S} 3$ indicate the ability of the devices to detect sub $5 \mathrm{ppm} \mathrm{NO}$ gas, Figure 7. The literature has reported on the polymer/ZnO sensor for $\mathrm{NO}_{2}$ sensing. Chougule and his group synthesized the polypyrrole- $\mathrm{ZnO}$ nanocomposite gas sensor [27]. The sensitivity of the sensor against $100 \mathrm{ppm} \mathrm{NO} 2$ was around 37\% at room temperature. Our ZnO-SU8 sensors responded with $36 \%$ variation in the sensing signal against much lower concentrations of $\mathrm{NO}_{2}$ (5 ppm). Wang reported the poly(3-hexylthiophene) (P3HT)/ZnO hybrid $\mathrm{NO}_{2}$ sensor [28]. The sensitivity reached $55 \%$ against $4 \mathrm{ppm} \mathrm{NO}$ gas, which is slightly higher than the sensitivity reported here because pure P3HT showed sensitivity against $\mathrm{NO}_{2}$. However, pure $\mathrm{HSQ}$ and $\mathrm{SU} 8$ polymer did not respond to $\mathrm{NO}_{2}$ gas.

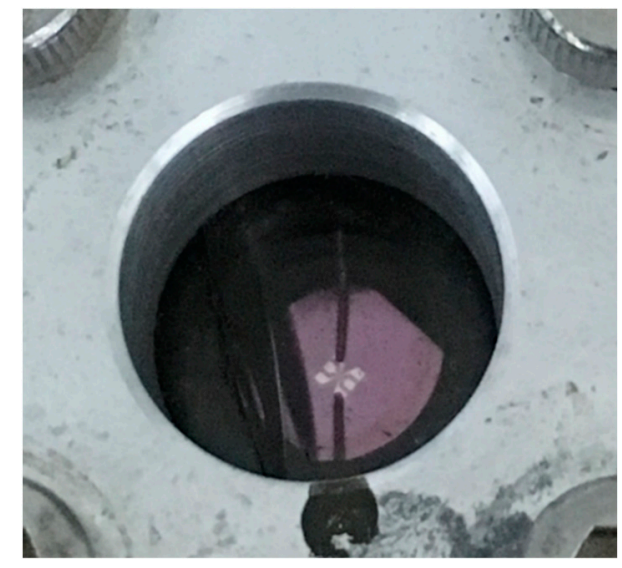

(a)

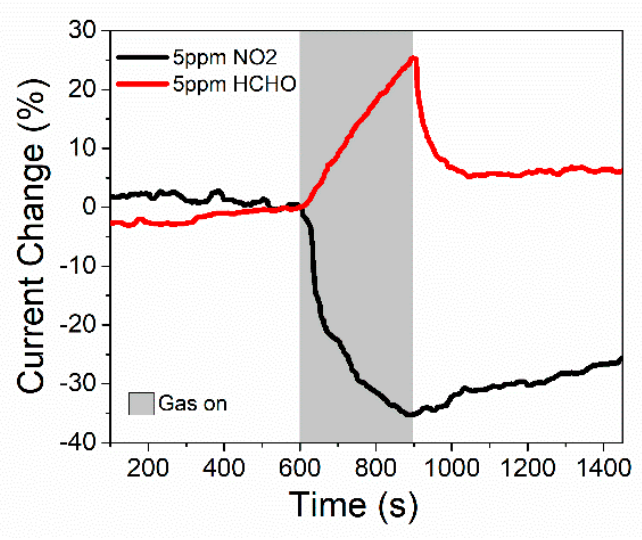

(b)

Figure 7. Gas sensing application of infiltrated devices. (a) First generation device in a gas sensing chamber. (b) Data showing the change of current (\%) as a function of time as the device is exposed to 5 ppm of formaldehyde and 5 ppm of $\mathrm{NO}_{2}$.

The current responses also suggest that the $\mathrm{ZnO}$ is n-type as formaldehyde is a reducing gas while $\mathrm{NO}_{2}$ is an oxidizing gas. The mechanism of sensing gases by $\mathrm{n}$-type $\mathrm{ZnO}$ can be explained by the oxygen ions' surface sorption model [29]. At room temperature, oxygen molecules from air are adsorbed on the surface of the zinc oxide. Carriers (electrons for $\mathrm{ZnO}$ ) are transferred from the conduction band of the n-type oxide semiconductor to the adsorbed oxygen atoms, and at room temperature, the dominant specie is $\mathrm{O}_{2}{ }^{-}$. During the exposure to $\mathrm{NO}_{2}$ gas, the gas molecules are adsorbed on the $\mathrm{ZnO}$ surface. $\mathrm{NO}_{2}$, as an oxidizing gas, acts as an acceptor of electrons $\left(2 \mathrm{NO}_{2}+\mathrm{O}_{2}{ }^{-}+2 \mathrm{e}^{-} \rightarrow 2 \mathrm{NO}_{3}{ }^{-}\right)$thus reducing the current [30]. When the metal oxide surface is exposed to formaldehyde gas, $\mathrm{O}_{2}{ }^{-}$reacts with the gas molecules and the electrons are released back to the conduction band $\left(\mathrm{HCHO}+2 \mathrm{O}_{2}{ }^{-} \rightarrow \mathrm{CO}_{2}+\mathrm{H}_{2} \mathrm{O}\right.$ $\left.(\mathrm{g})+4 \mathrm{e}^{-}\right)$, thus increasing the current [31]. When the surface-to-volume ratio is high, more $\mathrm{O}_{2}{ }^{-}$are adsorbed on the material surface, and the reaction between gas molecules and $\mathrm{O}_{2}{ }^{-}$species increases the sensitivity [32].

A dielectric core only device performance was compared with the performance of a device with infiltrated SU-8 polymer. In addition, a device with no mesh pattern was added so it is possible to determine if the increased mesh surface area has a significant effect on the device gas sensing performance, Figure 8. 


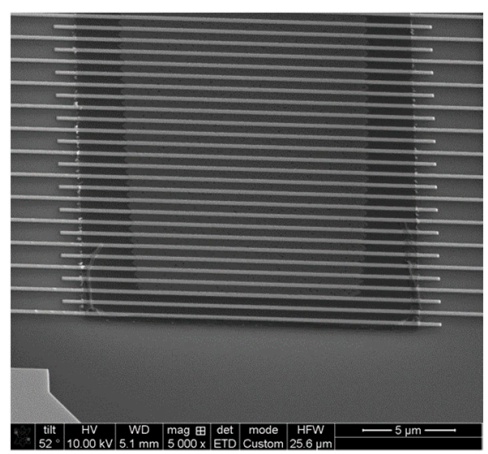

(a)

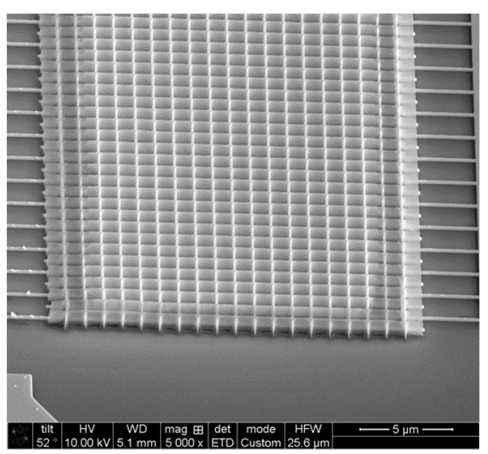

(b)

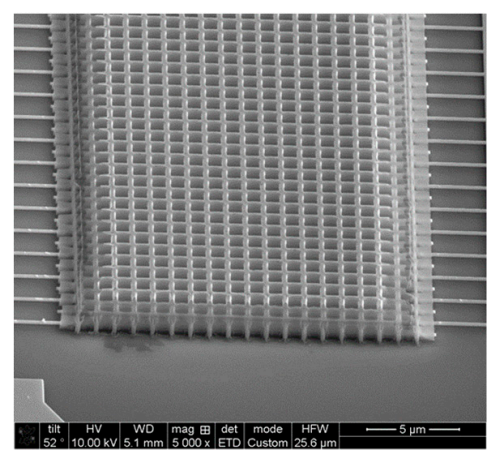

(c)

Figure 8. Set of devices to test the effects of the surface area, and polymer infiltration on the performance for gas sensing. (a) Thin film of $\mathrm{ZnO}$ over the interdigitated electrodes and no dielectric core mesh. (b) Dielectric core mesh coated with $\mathrm{ZnO}$. (c) SU-8 polymer with interior dielectric core mesh infiltrated with $\mathrm{ZnO}$.

The gas response results are shown in Figure 9a. It is clear from the data that the extra SU-8 polymer does not improve the response to the gas. The reason is that the interaction of the device to the gas is a surface effect. The polymer device has the same surface area as the dielectric core device. Figure 9 indicates that the device baseline during the gas sensing is not flat. We believe it is a thermal effect during measurement. The selectivity performance was investigated as shown in Figure $9 \mathrm{~b}$. The polymer device indicated a larger current change (21\%) in $\mathrm{NO}_{2}$ than in $\mathrm{NH}_{3}(\sim 2 \%)$ or $\mathrm{H}_{2}(\sim 10 \%)$ at same or even lower concentrations. We also found the device could detect $\mathrm{NO}_{2}$ gas lower than a 5 ppm concentration (Figure S3).

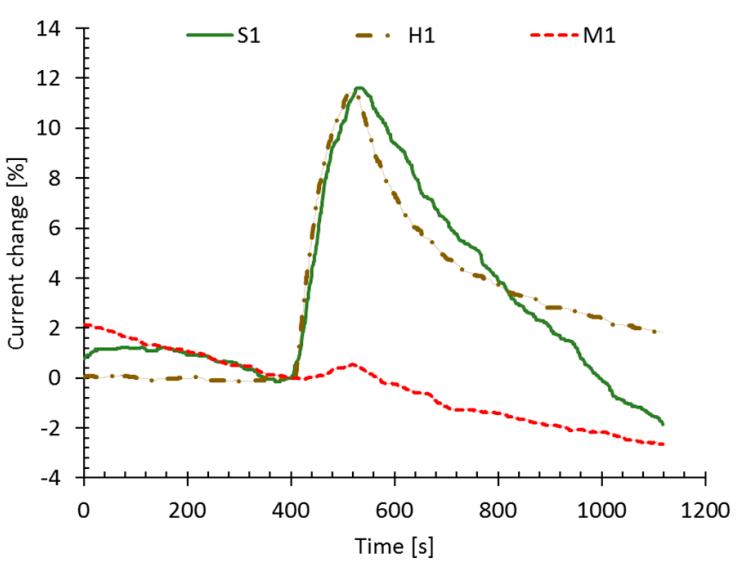

(a)

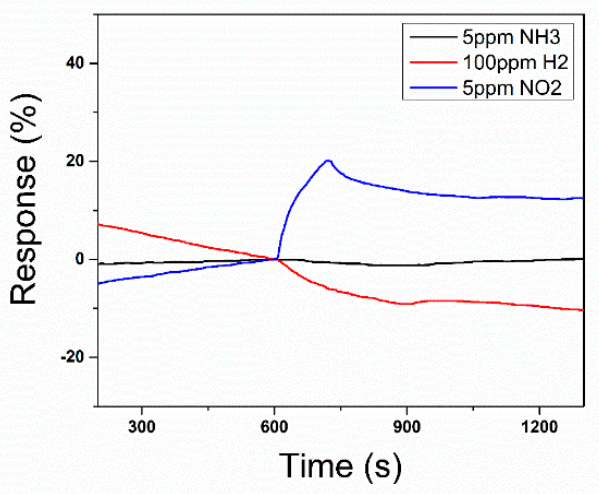

(b)

Figure 9. (a) Gas response plots to $5 \mathrm{ppm}$ of $\mathrm{NO}_{2}$ for the three types of devices as shown in Figure 8 . Data labeled M1 corresponds to a device with no mesh. Data labeled H1 corresponds to a device with a dielectric core mesh. Data labeled S1 corresponds to a device with a dielectric core mesh and infiltrated SU-8 polymer. Data were normalized to the device response right before gas was turned on at $400 \mathrm{~s}$. (b) Gas response plots to $5 \mathrm{ppm} \mathrm{NH}_{3}, 5 \mathrm{ppm} \mathrm{NO}$, and $100 \mathrm{ppm}_{2}$ of the $\mathrm{S} 1$ sample.

\section{Summary and Conclusions}

This report has demonstrated that it is possible to make interesting sensing devices with infiltrated polymers when the interactions penetrate into the volume of the polymer. As such, we find that infiltrated devices with SU-8 polymer can make sensitive UV sensors. We also found that mesh dielectric core devices can make sensitive gas sensors with better than a $5 \mathrm{ppm}$ lower detection limit. The infiltrated devices could respond to $5 \mathrm{ppm} \mathrm{NO} \mathrm{NO}_{2}$ with a $\sim 12 \%$ current change. There is still room for further understanding of the interactions of the $\mathrm{ZnO}$ and the gases and improvement in the baseline 
stability of the device. A new type of p-n junction device that is highly sensitive to UV illumination was demonstrated, thus making it a more sophisticated UV sensor. We showed that devices with the infiltrated polymer can serve as transparent multifunctional sensors that are responsive to both UV and gases, with UV sensing throughout the volume of the infiltrated polymer while gas sensing occurs at the polymer surface.

Supplementary Materials: The following are available online at http://www.mdpi.com/1424-8220/19/9/2061/s1, Figure S1: SEM images of the sensor layout, Figure S2: Multi-cycled UV response curve of the ' $\mathrm{S}$ ' sample, Figure S3: Gas response plots to $1 \mathrm{ppm} \mathrm{NO2} \mathrm{of} \mathrm{S3} \mathrm{and} \mathrm{S4} \mathrm{samples.}$

Author Contributions: Conceptualization, L.E.O., J.C.; Methodology, L.E.O., Y.W., and J.C.; Software, L.E.O., Y.W., and J.C.; Validation, L.E.O., Y.W., and J.C.; Formal analysis, L.E.O., J.C.; Investigation, L.E.O., Y.W., and R.D.; Resources, L.E.O., J.C.; Data Curation, L.E.O., J.C.; Writing-Original Draft Preparation, L.E.O.; Writing-Review \&Editing, L.E.O., Y.W., R.D., and J.C.; Visualization, L.E.O., Y.W., R.D., and J.C.; Supervision, L.E.O., J.C.; Project Administration, L.E.O., J.C.; Funding Acquisition, L.E.O., J.C.

Funding: This work was partially supported by an NSF partnership for innovation grant (IIP-1701203) and performed, in part, at the Center for Nanoscale Materials, a U.S. Department of Energy Office of Science User Facility, and supported by the U.S. Department of Energy, Office of Science, under Contract No. DE-AC02-06CH11357. J. C. acknowledges support by (while serving at) the U.S. National Science Foundation.

Conflicts of Interest: The authors declare no conflict of interest.

\section{References}

1. Miller, D.R.; Akbar, S.A.; Morris, P.A. Nanoscale metal oxide-based heterojunctions for gas sensing: A review. Sens. Actuators B 2014, 204, 250-272. [CrossRef]

2. Liu, M.; Nam, C.-Y.; Black, C.T.; Kamcev, J.; Zhang, L. Enhancing water splitting activity and chemical stability of zinc oxide nanowire photoanodes with ultrathin titania shells. J. Phys. Chem. C 2013, 117, 13396-13402. [CrossRef]

3. Liu, L.; $\mathrm{Li}, \mathrm{Y}$. Understanding the reaction mechanism of photocatalytic reduction of $\mathrm{CO}_{2}$ with $\mathrm{H}_{2} \mathrm{O}$ on $\mathrm{TiO}_{2}$-based photocatalysts: A Review. Aerosol Air Qual. Res. 2014, 14, 453-469. [CrossRef]

4. Djurišić, A.B.; Ng, A.M.C.; Chen, X.Y. ZnO nanostructures for optoelectronics: Material properties and device applications. Prog. Quantum Electron. 2010, 34, 191-259. [CrossRef]

5. Fan, J.C.; Chang, S.L.; Xie, Z. ZnO-Based Light-Emitting Diodes. Optoelectronics-Advanced Materials and Devices; Pyshkin, S.L., Ballato, J.M., Eds.; InTech: Rijeka, Croatia, 2013; Chapter 2; p. 25.

6. Chorfi, H.; Saadoun, M.; Bousselmi, L.; Bessais, B. $\mathrm{TiO}_{2}-\mathrm{ITO}$ and $\mathrm{TiO}_{2}-\mathrm{ZnO}$ nanocomposites: Application on water treatment. EPJ Web Conf. 2012, 29, 00015. [CrossRef]

7. Comarmond, M.J.; Payne, T.E.; Harrison, J.J.; Thiruvoth, S.; Wong, H.K.; Aughterson, R.D.; Lumpkin, G.R.; Müller, K.; Foerstendorf, H. Uranium sorption on various forms of titanium dioxide-Influence of surface area, surface charge and impurities. Environ. Sci. Technol. 2011, 45, 5536-5542. [CrossRef]

8. Arya, S.K.; Saha, S.; Ramirez-Vick, J.E.; Gupta, V.; Bhansali, S.; Singh, S.P. Recent advances in ZnO nanostructures and thin films for biosensor applications: Review. Anal. Chim. Acta 2012, 737, 1-21. [CrossRef] [PubMed]

9. Fortunato, E.; Barquinha, P.; Martins, R. Oxide Semiconductor Thin-Film Transistors: A Review of Recent Advances. Adv. Mater. 2012, 24, 2945-2986. [CrossRef]

10. Chaieb, A.; Chari, A.; Sahraoui, B. Optical properties of $\mathrm{ZnO}$ nanocrystals embedded in PMMA. Opt. Quantum Electron. 2014, 46, 39-46. [CrossRef]

11. Soumya, S.; Mohamed, A.P.; Paul, L.; Mohan, K.; Ananthakumar, S. Near IR reflectance characteristics of PMMA/ZnO nanocomposites for solar thermal control interface films. Sol. Energy Mater. Sol. Cells 2014, 125, 102-112. [CrossRef]

12. Paramo, J.A.; Strzhemechny, Y.M.; Anžlovar, A.; Žigon, M.; Orel, Z.C. Enhanced room temperature excitonic luminescence in $\mathrm{ZnO} /$ polymethyl methacrylate nanocomposites prepared by bulk polymerization. J. Appl. Phys. 2010, 108, 023517. [CrossRef]

13. Japić, D.; Djerdj, I.; Marinšek, M.; Orel, Z.C. In situ and ex situ TEOS coating of ZnO nanoparticles and the preparation of composite ZnO/PMMA for UV-VIS absorbers. Acta Chim. Slov. 2013, 60, 797-806. 
14. Peng, Q.; Tseng, Y.-C.; Darling, S.B.; Elam, J.W. A route to nanoscopic materials via sequential infiltration synthesis on block copolymer templates. ACS Nano 2011, 5, 4600-4606. [CrossRef]

15. Ocola, L.E.; Connolly, A.D.; Gosztola, J.; Schaller, R.D.; Yanguas-Gil, A. Infiltrated Zinc Oxide in Poly(methyl methacrylate): An Atomic Cycle Growth Study. J. Phys. Chem. C 2017, 121, 1893-1903. [CrossRef]

16. Ye, X.; Kestell, J.; Kisslinger, K.; Liu, M.; Grubbs, R.B.; Boscoboinik, J.A.; Nam, C.-Y. Effects of Residual Solvent Molecules Facilitating the Infiltration Synthesis of $\mathrm{ZnO}$ in a Nonreactive Polymer. Chem. Mater. 2017, 29, 4535-4545. [CrossRef]

17. Weber, M.; Julbe, A.; Ayral, A.; Miele, P.; Bechelany, M. Atomic Layer Deposition for Membranes: Basics, Challenges, and Opportunities. Chem. Mater. 2018, 30, 7368-7390. [CrossRef]

18. Nam, C.-Y.; Stein, A.; Kisslinger, K. Direct fabrication of high aspect-ratio metal oxide nanopatterns via sequential infiltration synthesis in lithographically defined SU-8 templates. J. Vac. Sci. Technol. B 2015, 33, 06F201. [CrossRef]

19. Nam, C.-Y.; Stein, A.; Kisslinger, K.; Black, C.T. Electrical and structural properties of ZnO synthesized via infiltration of lithographically defined polymer templates. Appl. Phys. Lett. 2015, 107, 203106. [CrossRef]

20. Ocola, L.E.; Gosztola, D.J.; Yanguas-Gil, A. A Polymer-Hybrid Electro-Optic Devices and Method of Fabricating Polymer-Hybrid Electro-Optic Devices. US Patent 10164188, 25 December 2018.

21. Lu, G.H.; Ocola, L.E.; Chen, J.H. Room-Temperature Gas Sensing through Electronic Transfer between Discrete Tin Oxide Nanocrystal and Multiwalled Carbon Nanotube. Adv. Mater. 2009, 21, 2487-2491. [CrossRef]

22. Wang, R.; Tan, H.; Zhao, Z.; Zhang, G.; Song, L.; Dong, W.; Sun, Z. Stable ZnO@TiO 2 core/shell nanorod arrays with exposed high energy facets for self-cleaning coatings with anti-reflective properties. J. Mater. Chem. A 2014, 2, 7313-7318. [CrossRef]

23. Dai, J.; Xu, C.; Xu, X.; Guo, J.; Li, J.; Zhu, G.; Lin, Y. Single ZnO microrod ultraviolet photodetector with high photocurrent gain. ACS Appl. Mater. Interfaces 2013, 5, 9344-9348. [CrossRef] [PubMed]

24. Soci, C.; Zhang, A.; Xiang, B.; Dayeh, S.A.; Aplin, D.P.; Park, J.; Bao, X.Y.; Lo, Y.H.; Wang, D. ZnO Nanowire UV Photodetectors with High Internal Gain. Nano Lett. 2007, 7, 1003-1009. [CrossRef] [PubMed]

25. ThermoFisher Scientific Safety Data Sheet Formaldehyde solution 37\%. Available online: https://www.fishersci.com/store/msds?partNumber=S25329\&productDescription=formaldehyde-solution\&vendorId=VN00115888\&keyword=true\&countryCode=US\&language=en (accessed on 28 April 2019).

26. Praxair, Nitrogen dioxide, Safety Data Sheet. Available online: https://www.praxair.com/-/media/corporate/ praxairus/documents/sds/nitrogen/nitrogen-dioxide-no2-and-n2o4-safety-data-sheet-sds-p4633.pdf?rev= a50e30f97ceb40c7a8340ecb79d2ec14 (accessed on 28 April 2019).

27. Chougule, M.A.; Dalavi, D.S.; Mali, S.; Patil, P.S.; Moholkar, A.V.; Agawane, G.L.; Kim, J.H.; Sen, S.; Patil, V.B. Novel method for fabrication of room temperature polypyrrole-ZnO nanocomposite $\mathrm{NO}_{2}$ sensor. Measurement J. Int. Meas. Confed. 2012, 45, 1989-1996. [CrossRef]

28. Wang, J.; Li, X.; Xia, Y.; Komarneni, S.; Chen, H.; Xu, J.; Xiang, L.; Xie, D. Hierarchical ZnO Nanosheet-Nanorod Architectures for Fabrication of Poly(3-hexylthiophene)/ZnO Hybrid $\mathrm{NO}_{2}$ Sensor. ACS Appl. Mater. Interfaces 2016, 8, 8600-8607. [CrossRef]

29. Kannan, P.K.; Saraswathi, R. An impedance sensor for the detection of formaldehyde vapor using $\mathrm{ZnO}$ nanoparticles. J. Mater. Res. 2017, 82, 2800-2809. [CrossRef]

30. Xia, Y.; Wang, J.; Li, X.; Xie, D.; Zhou, D.; Xiang, L.; Komarneni, S. Nanoseed-assisted rapid formation of ultrathin $\mathrm{ZnO}$ nanorods for efficient room temperature $\mathrm{NO}_{2}$ detection. Ceram. Int. 2016, 42, 15876-15880. [CrossRef]

31. Zou, Z.; Qiu, Y.; Xu, J.; Guo, P.; Luo, Y.; Wang, C. Enhanced formaldehyde photoelectric response on ZnO film illuminated with visible light. J. Alloys Compd. 2017, 695, 2117-2123. [CrossRef]

32. Su, X.; Gao, L.; Zhou, F.; Cai, W.; Duan, G. "Close network" effect of a ZnO micro/nanoporous array allows high UV-irradiated $\mathrm{NO}_{2}$ sensing performance. RSC Adv. 2017, 7, 21054-21060. [CrossRef]

(C) 2019 by the authors. Licensee MDPI, Basel, Switzerland. This article is an open access article distributed under the terms and conditions of the Creative Commons Attribution (CC BY) license (http://creativecommons.org/licenses/by/4.0/). 